\title{
Author Correction: Evolution of placental invasion and cancer metastasis are causally linked
}

Kshitiz (D), Junaid Afzal, Jamie D. Maziarz, Archer Hamidzadeh, Cong Liang (D), Eric M. Erkenbrack (D), Hong Nam Kim, Jan-Dirk Haeger, Christiane Pfarrer, Thomas Hoang, Troy Ott, Thomas Spencer (D), Mihaela Pavličev, Douglas F. Antczak, Andre Levchenko (D) and Günter P. Wagner (D)

Correction to: Nature Ecology \& Evolution https://doi.org/10.1038/s41559-019-1046-4, published online 25 November 2019.

In the version of this Article originally published, the name of author 'Hong Nam Kim' was mistakenly written as 'Hong Nam'. This has now been corrected.

Published online: 16 January 2020

https://doi.org/10.1038/s41559-020-1100-2

(c) The Author(s), under exclusive licence to Springer Nature Limited 2020 